\title{
Aortic Aneurysm Disease - Make Room for Chronobiology
}

\author{
Aleksandra Lopuszko ${ }^{1}$, Cian Tan ${ }^{1}$, Wahaj Munir ${ }^{1}$, and Mohamad Bashir ${ }^{2}$ \\ ${ }^{1}$ Queen Mary University of London Barts and The London School of Medicine and \\ Dentistry \\ ${ }^{2}$ Royal Blackburn Teaching Hospital
}

February 23, 2021

\begin{abstract}
Background Aortic Aneurysm (AA) is a common atherosclerotic condition, accounting for nearly 6,000 deaths in England and up to 175,000 deaths globally each year. The pathological outward bulging of the aorta typically results from atherosclerosis or hereditary connective tissue disorders. AAs are usually asymptomatic until spontaneous rupture or detected on incidental screening. 8 in 10 patients do not survive the rupture and die either before reaching hospital or from complications following surgery. Similar to other cardiovascular pathologies (CVPs), AA is thought to be subject to chronobiological patterns of varying incidence. Methods We performed a literature review of the current literature to evaluate the association between circadian rhythms, seasonal variations, and genetic factors and the pathogenesis of AA, reviewing the impact of chronobiology. Results The incidence of AA is found to peak in the early morning (6 AM - 11 AM) and colder months, and conversely troughs towards the evening and warmer months, exhibiting a similar pattern of chronobiological rhythm as other CVPs such as myocardial infarcts, or cerebrovascular strokes. Conclusion Literature suggests there exists a clear relationship between chronobiology and the incidence and pathogenesis of ruptured AA; incidence increases in the morning (6am - 11am), and during colder months (December - January). This is more pronounced in patients with Marfan Syndrome, or vitamin D deficiency. The underlying pathophysiology and implications this has for chronotherapeutics, are also discussed. Our review shows a clear need for further research into the chronotherapeutic approach to preventing ruptured AA in the journey towards precision medicine.
\end{abstract}

\section{Hosted file}

ChronobiologyAA.pdf available at https://authorea.com/users/397611/articles/510438-aorticaneurysm-disease-make-room-for-chronobiology

\section{Hosted file}

ChronobiologyAATable1.pdf available at https://authorea.com/users/397611/articles/510438aortic-aneurysm-disease-make-room-for-chronobiology

\section{Hosted file}

ChronobiologyAATable2.pdf available at https://authorea.com/users/397611/articles/510438aortic-aneurysm-disease-make-room-for-chronobiology

\section{Hosted file}

ChronobiologyAATable3.pdf available at https://authorea.com/users/397611/articles/510438aortic-aneurysm-disease-make-room-for-chronobiology 